where there has been close contact with pigs, but this is the first report of its case-to-case transmission. If this virus should spread, and if it retains or acquires the virulence for man of the 1918 virus, then the world could be faced with a similar pandemic. The 1918-19 influenza pandemic not only caused many deaths among the elderly but also an unusually high mortality in young adults. ${ }^{5}$ At the present time many people over about 50 years of age possess serum antibodies against the swine virus; a swine influenza pandemic now might therefore spare older people, but younger adults and children would be expected to possess no basal immunity.

The epidemiological features of the swine influenza virus are under close scrutiny by the Centre for Disease Control in Atlanta, USA, and by the World Health Organisation. Plans are in hand to start large-scale production of killed vaccine if evidence of significant spread appears. Careful observation is being kept in Britain, where the Department of Health, the Medical Research Council, and the Public Health Laboratory Service, together with vaccine manufacturers and field workers, are also putting preliminary plans into operation. Small amounts of killed vaccine are being made for clinical trials-in order, for example, to determine the dose that will ensure an adequate serological response, particularly in young adults and children who might respond poorly to a completely new influenza vaccine; they may require two injections. Live, attenuated vaccines will also be prepared, though they may well not be available soon enough to combat the first effects of a pandemic because their development and the essential potency and safety testing takes time. Nevertheless, their study is important; many workers believe that the eventual control of pandemic influenza is most likely to be achieved by means of live vaccines which can be given easily and economically by the nasal route.

1 Bulletin of the World Health Organisation, 1971, 45, 119.

2 Pereira, M S, et al, Fournal of Hygiene, 1969, 67, 551.

3 Kilbourne, E D, fournal of Infectious Diseases, 1973, 127, 478.

${ }^{4}$ US Department of Health, Education and Welfare, Morbidity and Mortality Weekly Report, 1976, 25, 47.

${ }^{5}$ Ministry of Health, Reports on Public Health and Medical Subjects No 4. London, HMSO, 1920.

\section{Oxygen in myocardial infarction}

Patients with acute myocardial infarction commonly have hypoxaemia, and this tends to be more pronounced when left ventricular failure or shock complicates the infarct. ${ }^{1-3}$ Severe hypoxaemia is associated with a higher incidence of cardiac arrhythmias and a higher mortality. Several mechanisms have been proposed to explain the hypoxaemia; imbalance of ventilation-perfusion, collapse of small airways with physiological right-to-left shunting, and pulmonary oedema. Oxygen treatment restores the arterial oxygen tension to normal more readily in uncomplicated cases than in those in which there is left ventricular failure or shock, and it usually results in increased total peripheral resistance, a rise in the arterial pressure, and a reduction in cardiac output. ${ }^{3} 4$

Oxygen is given routinely to many patients with myocardial infarction, but there is still no evidence based on controlled clinical trials about its effect on either morbidity or mortality. It seems reasonable to correct hypoxaemia and even to achieve higher-than-normal arterial oxygen tensions in the belief that more oxygen would then be available to the myocardium.
This might be expected to reduce the incidence of arrhythmias and the size of the infarct, improve myocardial performance, and reverse metabolic acidosis by improving aerobic respiration in other organs such as skeletal muscle. ${ }^{45}$ Whether or not these results do occur, however, remains controversial.

Based on work in dogs, Maroko and co-workers ${ }^{6}$ have recently suggested that $40 \%$ inspired oxygen might benefit patients with uncomplicated myocardial infarction. They found a significant reduction in the extent of acute ischaemic injury and in the size of myocardial infarcts produced by occlusion of the left anterior descending artery in dogs breathing $40 \%$ oxygen (resulting in a $\mathrm{PaO}_{2}$ of $25 \mathrm{kPa}(188 \mathrm{~mm} \mathrm{Hg})$ ) when compared with dogs breathing $20 \%$ oxygen $\left(\mathrm{PaO}_{2}\right.$ $13 \mathrm{kPa}(98 \mathrm{~mm} \mathrm{Hg}))$; the inhalation of $100 \%$ oxygen offered no added advantage. The same group has also shown that hypoxaemia $\left(\mathrm{PaO}_{2}<6 \mathrm{kPa}(<45 \mathrm{~mm} \mathrm{Hg})\right)$ substantially increased myocardial damage, ${ }^{7}$ though Madias et $a l^{8}$ found that hypoxaemia did not further depress ventricular function after myocardial infarction. The results of these studies $^{6} 7$ are encouraging, but relatively few animals were used and several questions are left unanswered. The oxygen inhalation was given for only 24 hours, and its protective effect over a longer period would be of interest. Since most patients with acute myocardial infarction do not come under medical care immediately after the infarct it is also important to know whether the protective effect of $40 \%$ oxygen inhalation is influenced by a delay of several hours.

Controlled clinical trials in man seem warranted before such treatment could be recommended with confidence. The information we have at present about the value of oxygen inhalation is conflicting. Some investigators state that inhalation of $100 \%$ oxygen does not augment the availability of oxygen to the myocardium in patients with coronary artery disease (nor in patients with rheumatic or congenital heart disease) and may in patients with triple coronary artery disease ${ }^{9}$ even reduce coronary blood flow sufficiently to increase myocardial ischaemia. On the other hand, Horvat et $a l^{10}$ showed an increase in the threshold of pacing-induced angina by oxygen inhalation, and Ganz et al ${ }^{11}$ found a beneficial effect of high oxygen concentration $\left(\mathrm{PaO}_{2}>53 \mathrm{kPa}(>398 \mathrm{~mm} \mathrm{Hg})\right)$ in coronary disease.

Hyperbaric oxygen is probably of marginal, if any, value in patients with acute myocardial infarction. ${ }^{12} 13$ Thurston and his co-workers ${ }^{13}$ did appear to show some reduction in mortality in patients treated with hyperbaric oxygen compared with those given oxygen via an MC mask, but the evidence available suggests that, even if it were feasible, this form of treatment cannot be recommended for wide use.

Mild hypoxaemia can be corrected easily by using nasal catheters or cannulae at a flow rate of $1-21 / \mathrm{min}$ or a Ventimask delivering $24-28 \%$ oxygen at $4 \mathrm{l} / \mathrm{min}^{1415}$ These devices are particularly helpful for patients with chronic respiratory disease, in whom hyperoxaemia should be avoided. ${ }^{16}$ For more profound hypoxaemia the MC mask will deliver about $60 \%$ oxygen and achieve a $\mathrm{PaO}_{2}$ of $25 \pm 5.5 \mathrm{kPa}(188 \pm$ $41 \mathrm{~mm} \mathrm{Hg}) \cdot{ }^{17}$ Delivery of $40 \%$ oxygen can be achieved by a $40 \%$ Venturi mask, an MC or Edinburgh mask at 4-6 1/min, or nasal cannulae at $4 \mathrm{1} / \mathrm{min} .^{115}$ Whichever device is used arterial oxygen tension should be measured in the more severely ill patients, and administration should be continued for three days or longer if the patient's condition warrants it. $^{14}$

The uncertainty about the value of oxygen therapy is shown clearly enough by the range of practices in different coronary care units, most of which report similar mortality rates. Except when carbon dioxide retention is present, the most 
frequent policy is to give oxygen in high dosage to those with heart failure or shock, and this seems to be justified by the improvement which results in arterial oxygen tension. Many coronary care units routinely use oxygen for the first few hours or days in all patients after acute myocardial infarction, and there is no evidence to suggest that this is harmful, or that it is definitely beneficial.

1 Tonkin, A M, Wilson, D F, and Richmond, D R, Australian and New Zealand Fournal of Medicine, 1973, 3, 593.

${ }^{2}$ McNicol, M W, et al, British Medical fournal, 1965, 2, 1270.

3 Kenmure, A C F, et al, British Medical fournal, 1968, 4, 360

$4 \mathrm{McNicol}, \mathrm{M}$ W, and Kirby, B J, in Textbook of Coronary Care, ed L E Meltzer, and A J Dunning, p 521. Amsterdam, Excerpta Medica, 1972. 5 Koerner, S K, American Heart fournal, 1971, 82, 269.

- Maroko, R, et al, Circulation, 1975, 52, 360.

${ }^{7}$ Radvany, P, Maroko, P R, and Braunwald, E, American fournal of Cardio$\log y, 1975,35,795$.

${ }^{8}$ Madias, J E, et al, American fournal of Cardiology, 1974, 34, 796.

- Bourassa, M G, et al, American fournal of Cardiology, 1969, 24, 172.

10 Horvat, M, et al, Circulation, 1972, 45, 837.

11 Ganz, W, et al, Circulation, 1972, 45, 763.

12 Cameron, A J V, in Textbook of Coronary Care, ed L E Meltzer and A J Dunning, p 570. Amsterdam, Excerpta Medica, 1972.

13 Thurston, J G B, et al, Quarterly fournal of Medicine, 1973, 42, 751.

14 Green, I D, British Medical fournal, 1967, 3, 593.

15 Woo, S W, and Hedley-Whyte, J, British Fournal of Hospital Medicine, $1973,9,487$.

16 British Medical fournal, 1972, 4, 480.

17 Lancaster, R, and McNicol, M W, Postgraduate Medical fournal, 1967, 43, 706 .

\section{Cover out of hours}

Night and weekend general practice services in Britain are generally organised on a different basis to that in most other European countries. ${ }^{1}$ Few, if any, British GPs still provide a personal 24-hour cover for their own patients; most doctors use an extended cover system ${ }^{2}$ in which the doctors in one practice or in a group of neighbouring practices share the responsibility for night calls on a rota basis. About one general practitioner in three ${ }^{3}$ contracts for all or part of his emergency work to be done by doctors employed by one of the commercial deputising services.

In a recent review of off-duty arrangements in Holland, Scandinavia, and Britain ${ }^{4} \mathrm{Hall}$ has argued that if general practice is to remain and develop as a specialty in its own right it should continue to take on the whole responsibility for primary medical care on a collective basis. Is it, however, any longer reasonable to expect the same doctor to be on call at night, even only once a week, when that duty has to be sandwiched between two full 8-12 hour working days ? No longer can it be taken for granted that it is only "good general practice"s when the same team of doctors is responsible 24 hours a day. Surely in the light of practice in other countries we should re-examine that part of the NHS terms of services which makes each GP responsible for the medical needs of his patients 24 hours a day, seven days a week, 52 weeks a year-whether or not he himself is on call.

In Scandinavia family doctors are responsible for their patients only between the hours of 8 or 9 am and 4 or $5 \mathrm{pm}$. Outside these hours other arrangements exist. In some districts there is a night first-aid post to which all emergencies -medical or surgical-have to be taken, if necessary by ambulance. In other areas a team of doctors (usually junior hospital doctors and yourger general practitioners wanting to supplement their incomes) are organised in the same way as the deputising services in Britain, except that in Scandinavia these doctors are not deputies, they are employed directly by the State. The patient may have to pay a fee, identical to that which he would have paid his doctor had the latter provided the service. These fees have some deterrent effect; the abolition of charges in Denmark in 1973 led to a $24 \%$ increase in the number of night calls. ${ }^{6}$ However, much of that increase seems to have been among the underprivileged, suggesting that the fees had been acting as a deterrent to those in need. Another point of interest was the finding that the volume of night calls per 1000 patients at risk was three to eight times greater than in Britain.

In the Netherlands the organisation of general practice is more like that in Britain. ${ }^{4}$ Patients (other than the $30 \%$ of the population in the upper income bracket who have to be private patients) register with a doctor of their choice, who is also responsible for night calls. In many towns the GPs collaborate in providing a complete emergency service for both their health service and private patients. For example, in The Hague, where the scheme became operative during the last war, an individual doctor is on call about one night every $3 \frac{1}{2}$ weeks. All the doctors on duty (four between the hours of $7 \mathrm{pm}$ and $1 \mathrm{am}$ and three between $1 \mathrm{am}$ and 7 am covering a population of 550000 ) spend the night at a central hospital. One of the duty GPs answers the phone: up to $60 \%$ of the queries are dealt with without the patient having to see the doctor. This contrasts remarkably with the procedure in Scandinavia, where most requests result in a consultation. Presumably this reflects differences in the method of remuneration. Of the patients seen during the night in The Hague, about one in three can come to the hospital to see the GP, and the rest are visited in their homes.

Would both doctors and their patients in Britain be better served by the adaptation of The Hague system? In effect, this would provide extended cover service for an area or district; perhaps the doctors on duty might then be relieved of their own practice responsibilities the day before and the day after they are on call.

As beauty is in the eye of the beholder, so what appears an emergency to the patient may not look as urgent to the doctor. Two recent papers ${ }^{78}$ have attempted to define the degree of medical urgency in a series of night calls in Britain. Unfortunately, the authors used different criteria of need and their analyses covered different hours, so that no real comparison of their findings can be made. More data are needed. Perhaps the RCGP and its sister organisations throughout the world will have this as one topic in mind when they discuss research at the Seventh World Conference on General Practice in Toronto next October; they could also, perhaps, look at studies of the alleged misuse of casualty or accident and emergency departments.

We also have to ask how much emergency work can, or should, be left to trainees, remembering that they will have to learn about the problems peculiar to night calls, ${ }^{9}$ and indeed what training is necessary and appropriate for those who work for deputising services.

Fournal of the Royal College of General Practitioners, 1976, 26, 162.

2 fournal of the Royal College of General Practitioners, 1976, 26, 3.

3 Department of Health and Social Security, General Medical Services. London, HMSO, 1973.

${ }^{4}$ Hall, D W, fournal of the Royal College of General Practitioners, 1976, 26, 19.

5 Taylor, S, Good General Practice. London, Oxford University Press, 1954.

6 Bentzen, N, Russell, I, and Spark, M G, Fournal of the Royal College of General Practitioners, 1976, 26, 37.

' Lockstone, D R, Fournal of the Royal College of General Practitioners, $1976,26,68$.

8 Gabriel, R, Fournal of the Royal College of General Practitioners, 1976, 26, 74.

' Clyne, M B, Night Calls. London, Tavistock Publications, 1961. 